\section{On the Thermo-Electrical Modeling of Small Satellite's} Solar Panels

\author{
ALEJANDRO M. GOMEZ-SAN-JUAN \\ JAVIER CUBAS \\ SANTIAGO PINDADO \\ Universidad Politécnica de Madrid, ETSI Aeronáutica y del Espacio, \\ Madrid, Spain
}

The thermal modeling of small satellites (up to $100 \mathrm{~kg}$ ) is crucial for predicting and managing their operation, and may present significant differences when compared to the thermal modeling carried out in relation to larger spacecraft. In this article, the modeling of their solar panels is underlined as one of these differences. The efficiency of spacecraft solar panels is affected by three main variables: the sun's irradiance, the cells' temperatures, and the operating voltage. Unlike the most common approach, which only takes into account the first two variables and decouples the thermal problem from the electrical one, the coupled thermo-electric problem of the solar panel efficiency as a whole is considered in this article. Using the UPMSat-2 mission as an example, the importance of considering the operating voltage in the thermal analysis of a mission is proven in the present article (for the prediction of temperature and generated power). A simple but accurate $I-V$ (Current-Voltage) curve model to calculate panel efficiency is proposed for modeling the solar panels performance, this method being easily implemented in ESATAN ${ }^{\odot}$.

Manuscript received June 18, 2020; revised October 16, 2020; released for publication December 9, 2020.

DOI. No. 10.1109/TAES.2020.3048797

Refereeing of this contribution was handled by R. Meyer.

This work was supported by the European Regional Development Fund (European Union) through the INTERREG-SUDOE V-B Program under Project NANOSTAR.

Authors' address: Alejandro M. Gomez-San-Juan is with the Instituto Universitario de Microgravedad "Ignacio Da Riva," Universidad Politécnica de Madrid, ETSI Aeronáutica y del Espacio, 28040 Madrid, Spain, E-mail: (alejandro.gomez@upm.es); Javier Cubas and Santiago Pindado are with the Instituto Universitario de Microgravedad "Ignacio Da Riva" and Departamento de Sistemas Aeroespaciales, Transporte Aéreo y Aeropuertos, Universidad Politécnica de Madrid, ETSI Aeronáutica y del Espacio, 28040 Madrid, Spain, E-mail: (j.cubas@upm.es; santiago.pindado@upm.es); (Corresponding author: Alejandro M. Gomez-San-Juan.)

0018-9251 @ 2021 IEEE

\section{INTRODUCTION}

During the last decade, small satellites (too small to be the standalone payload) have become a relevant fraction of the spacecraft launched every year and continue to increase. A total of 244 new nanosatellites were successfully launched in 2018, and more than 400 were announced for 2019. Furthermore, the number of launched nanosatellites is expected to reach 700 in 2023 [1]. The main reason behind this success is a great cost reduction, which makes space-based commercial and scientific activities an actual possibility for many new actors that previously could not afford them. This cost reduction is achieved by means of miniaturization, which also implies a large reduction of mass and standardization of components. The power subsystem is a typical example of standardized parts and components. In almost every small satellite, this subsystem is composed of solar panels (see Fig. 1), a battery, a cable harness, and a printed circuit board used as power distribution control system [2]. It is obvious that an adequate knowledge of the solar panels' behavior is key to efficient power management. Nevertheless, it should be underlined that proper knowledge of the solar panels' performance is equally important for the thermal modeling of the small satellite, something which is usually left aside in the design of this type of mission, because a simplified model is used [3]. This relationship between power generation and thermal effects represents a coupled problem, as the electric power delivered by a solar panel depends on its efficiency which, in turn, depends on the operating voltage $V$, the solar irradiance $G$, and the temperature of the solar cells $T$ [4]-[7].

The correct estimation of solar panels' efficiency is key in thermal analysis, as it determines how much energy received by the panel is translated into electric power and how much into heat. In current thermal studies of small satellites, the thermo-electric problem of solar panel efficiency is rarely completely analyzed. The following two possibilities are normally considered:

1) A constant efficiency, which may be considered a conservative approach for initial sizing [11], but it is inaccurate even for preliminary design.

2) A temperature dependent-efficiency, which may be adequate if the solar panel's power regulation system is Maximum Power Point Tracking (MPPT) [12]. This means that the output voltage of the solar panel is set at its Maximum Power Point (MPP) by varying the impedance to which the solar panel is connected [4], [5]. MPPT is often used in high cost spacecraft (such as scientific, military, or communications satellites), but it is not typically used in small-size and low-cost satellites. In these cases, Direct Energy Transfer (DET) power regulation is used instead. In DET systems, the solar panels are connected to a fixed operating voltage (which normally depends on the battery charge level), that sets the energy conversion efficiency of the panel [13], [14]. Most thermal models of low-cost satellites do not take the solar panels' operating voltage (their output voltage) into 

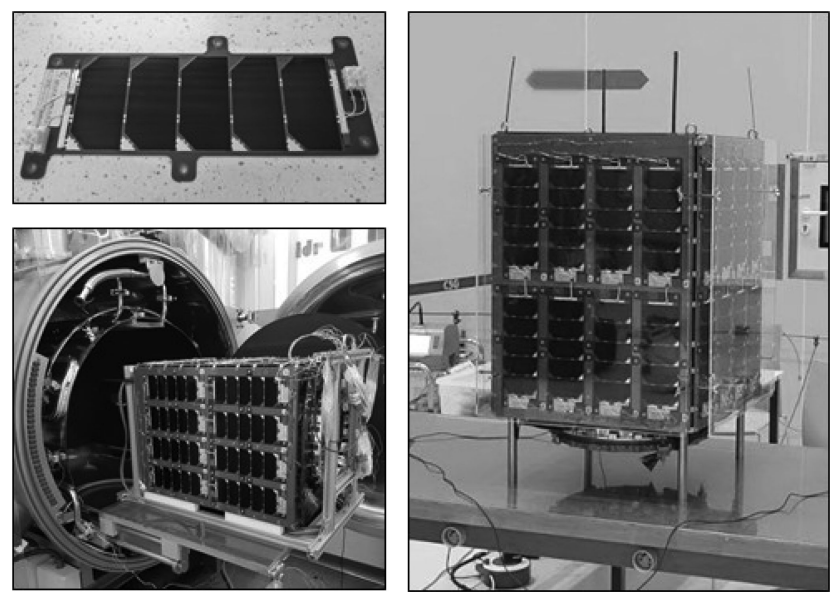

Fig. 1. Selex-Galileo SPVS 5-cell modules composed of Azur Space 3G28C solar cells (top-left). UPMSat-2 satellite [8]-[10] TVAC

(Thermal VAcuum Chamber) testing at IDR/UPM Institute (bottom-left). UPMSat-2 during integration tasks at the Centre Spatial Guyanais of CNES (Kourou, French Guiana, February 2020) (right).
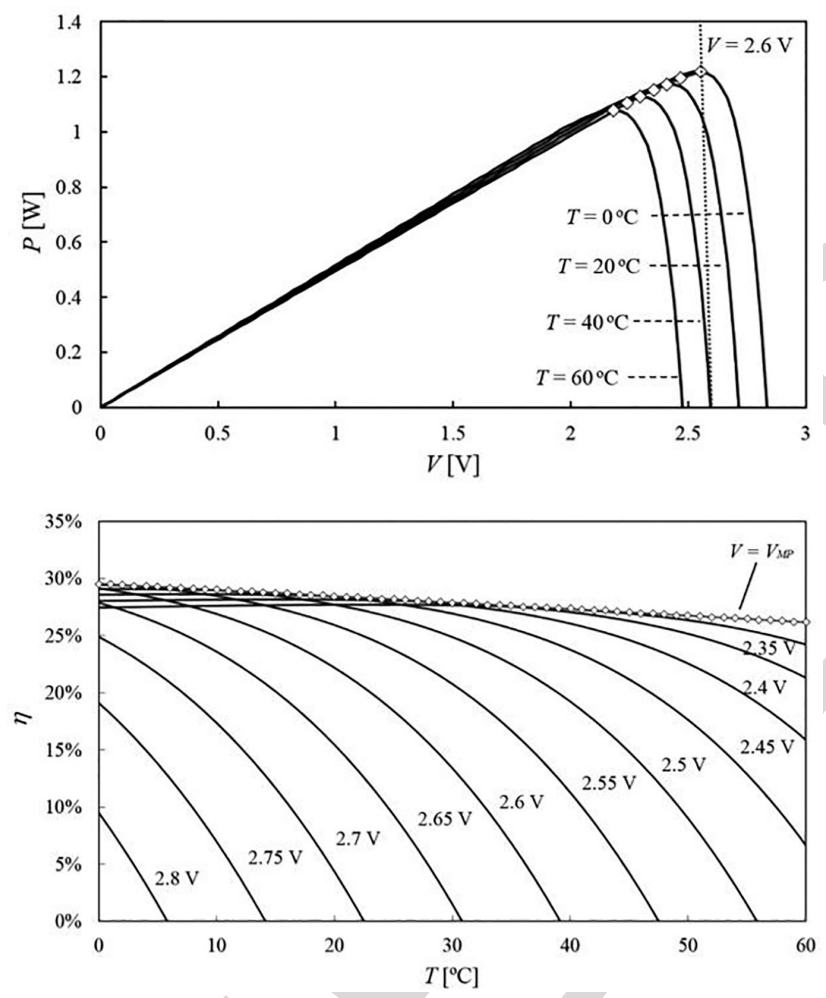

Fig. 2. Azur Space 3G28C solar cell. Power supplied $P$ versus output voltage $V(P-V$ curves $)$, for cell temperatures $T=0{ }^{\circ} \mathrm{C}, 20^{\circ} \mathrm{C}, 40{ }^{\circ} \mathrm{C}$, and $60{ }^{\circ} \mathrm{C}$. The MPP in each curve are indicated with open rhombi (top). Efficiency $\eta$, versus solar cell temperature $T$, for different cell output voltage levels $V$. The curve indicating the maximum possible efficiencies has been included in the graph with open rhombi (bottom).

account. However, changes in this variable might have a large effect on the efficiency. This could explain why so many small satellites have thermal failures, or produce less power than expected [15].

In Fig. 2, the power-voltage curves ( $P-V$ curves) of a single solar cell (3G28C Azur Space) are plotted for several cell temperatures. The importance of an accurate temperature prediction from thermal models is seen in this figure. The MPPs (one for each curve) are indicated with open diamonds. If this cell is connected to an impedance that imposes a 2.6 output voltage, maximum power would be supplied by the cell at $T=0{ }^{\circ} \mathrm{C}$. However, this supplied power would fall to zero if the temperature of the cell rises above $T=40{ }^{\circ} \mathrm{C}$. Furthermore, it should be underlined that even if the photovoltaic power production is prevented from falling to zero, the efficiency of the solar panels is significantly compromised by the output voltage level. The available power in a spacecraft with MPPT will move along the rhombi line when the temperature changes. On the other hand, since the voltage is fixed by the battery, the power in a spacecraft with a DET system will move over vertical lines like the dotted one for $2.6 \mathrm{~V}$. To analyze the behavior of this type of satellite, it is convenient to consider constant voltage lines in the thermal analysis.

The efficiency of the aforementioned solar cell $\eta$, is also plotted in Fig. 2 in relation to the temperature of the solar cell $T$, for a constant output voltage levels from $V=2.35 \mathrm{~V}$ to $V=2.8 \mathrm{~V}$. In this figure, it can be observed how different voltages cause high differences in panels' efficiency for the same temperature. Satellites with MPPT will always operate in the optimum voltage, therefore the efficiency of the panel for different temperatures will be along the diamond line. However, satellites with DET depend on the battery and combinations of high output voltages and high temperatures would have a strong negative impact on a satellite solar panels' efficiency. Furthermore, the decrease in the supplied power associated to the lower efficiency will lead to more heating of the panels which will in turn rise their temperature and decrease efficiency even more.

In this article, a thermo-electric model for DET satellites is proposed, the effect of the solar panel efficiency on the thermal problem being studied by using coupled analysis that takes into account the effect of the electrical problem in the thermal one and the effect of the thermal problem in the electrical one. The results included in this work are obtained by the following:

1) $\operatorname{ESATAN}^{\odot}$ modeling [16].

2) Programing the electric models of a satellite's solar cells assemblies and solar panels. These models have been previously correlated to experimental results [9], [17].

It should be underlined that $\operatorname{ESATAN}^{\odot}$ is the thermal analysis software required by the European Space Agency (ESA) in all its missions [18]. Many works in the available literature are an example of the use of this software to analyze thermal behavior of space systems [19]-[22]. The most relevant contribution of the present work is the achievement of thermo-electric coupled modeling programmed in ESATAN $^{\odot}$, that was made possible, thanks to the explicit method developed to analyze solar panel electrical behavior [17].

The UPMSat-2 satellite (see Fig. 1) is used as a case study in the present work. This is a $50 \mathrm{~kg}$ satellite developed by Instituto Universitario de Microgravedad "Ignacio Da 
TABLE I

UPMSat-2 Mission: Main Characteristics

\begin{tabular}{|c|c|}
\hline Mission Life & 2-year \\
\hline Orbit & $\begin{array}{l}\text { Sun-synchronous: } \\
\cdot \quad \text { 10:30 (almost noon) } \\
\text { - Altitude: } 530 \mathrm{~km} \\
\end{array}$ \\
\hline Mass & $50 \mathrm{~kg}$ \\
\hline Dimensions & $0.5 \mathrm{~m} \times 0.5 \mathrm{~m} \times 0.6 \mathrm{~m}$ \\
\hline Attitude Control & $\begin{array}{l}\text { Magnetic: } \\
\text { - SSBV magnetometers } \\
\text { - } \text { ZARM Technik AG magnetorquers } \\
\text { - } \quad \text { Control law designed by IDR/UPM }\end{array}$ \\
\hline Thermal Control & Passive \\
\hline Power & $\begin{array}{l}\text { Based on solar photovoltaic panels and } \\
\text { batteries: } \\
\text { S } 5 \text { body-mounted solar panels (Selex Galileo } \\
\text { SPVS- } 5 \text { modules with Azur Space } 3 \mathrm{G} 28 \mathrm{C} \\
\text { triple junction solar cells) } \\
\text { - } 18 \mathrm{~A} \cdot \mathrm{h} \text { Li-ion battery designed by SAFT } \\
\text { batteries } \\
\text { - Direct Energy Transfer (DET) }\end{array}$ \\
\hline $\begin{array}{l}\text { On board electronic } \\
\text { box (E-BOX) }\end{array}$ & $\begin{array}{l}\text { Based on FPGA (designed by Tecnobit S.L. } \\
\text { and programmed by STRAST/UPM). Includes: } \\
\text { - On-board computer } \\
\text { - Data handling } \\
\text { - Power supply control } \\
\text { - Power supply distribution }\end{array}$ \\
\hline Communications & $\begin{array}{l}\text { - Link at } 436 \mathrm{Mhz} \text { frequency } \\
\text { - } 4 \text { monopole antennae system } \\
\text { E-BOX } \\
\text { - Gomsys communication card installed in the } \\
\text { STRAST, hardware configuration supervised } \\
\text { by INTA }\end{array}$ \\
\hline Payload & $\begin{array}{l}\text { - Bartington magnetometer } \\
\text { - SSBV rotation wheel } \\
\text { - Iberespacio thermal microswitch } \\
\text { - Solar sensors }\end{array}$ \\
\hline
\end{tabular}

Riva" (IDR/UPM), which is a research institute integrated in Universidad Politécnica de Madrid (UPM). After a 1year delay caused by problems of the VEGA launcher, the Covid-19 disease, and the meteorology (winds) at high altitude, this mission was launched on September 2, 2020. The UPMSat-2 is a university-class microsatellite which serves both as a technological demonstrator and as a powerful pedagogical tool for the Master in Space Systems (MUSE - Máster Universitario en Sistemas Espaciales) from UPM University [8], [23]. The most relevant characteristics of this satellite are summarized in Table I.

Rest of this article is organized as follows. The electric model used for the thermo-electric coupled analysis and the different possible approaches to the thermo-electric problem are described in Section II. In Section III, results are included. These results are related to 1) a simple case analysis of a solar panel orbiting around the Earth; and 2) the thermo-electric problem associated to the UPMSat-2. The results are also discussed in this section. Finally, Section IV concludes this article.

\section{PROPOSED METHOD AND ANALYSIS}

A. Electric Modeling of Solar Panels

Before analyzing the thermo-electric problem of a solar panel, it is convenient to describe the selected electrical

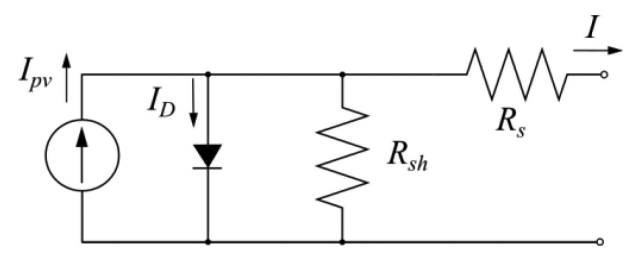

Fig. 3. 1-Diode/2-Resistor equivalent circuit of a solar panel.

model. A solar panel can be analyzed by means of an equivalent circuit. The most typical electric circuit equivalent to a photovoltaic device is comprised of an ideal current source, one diode and two resistors (see Fig. 3). The equation that defines the behavior of this 1-Diode/2-Resistor equivalent circuit is [24]:

$$
\begin{aligned}
I & =I_{p v}-I_{D}-\frac{V+I R_{s}}{I R_{s h}} \\
& =I_{p v}-I_{0}\left[\exp \left(\frac{V+I R_{s}}{a V_{T}}\right)-1\right]-\frac{V+I R_{s}}{I R_{s h}},
\end{aligned}
$$

where $I$ is the output current, $V$ is the output voltage, $R_{s}$ and $R_{s h}$ are the series and shunt resistors, $I_{p v}$ is the photocurrent delivered by the current source, and $I_{0}$ is the saturation current of the diode. Besides, $a$ is the ideality factor of the diode, and $V_{T}=n k T / q$ is the thermal voltage, in which $n$ is the number of series-connected cells of the photovoltaic device, $T$ is its temperature, $k$ is the Boltzmann constant, and $q$ is the charge of the electron [25].

One of the main issues to address when using this equation is obtaining the five parameters of the circuit: $I_{p v}$, $I_{0}, R_{s}, R_{s h}$, and $a$. Different methods have been proposed to solve this problem, attending to the source of the data used for the parameter extraction (experimental measurements of the photovoltaic device, manufacturer datasheet...) [26][29]. These parameters are not a group of constant figures. On the contrary, they depend on the temperature and the operating irradiance instead. This, together with the implicit formulation of the problem, makes the coupled analysis of the thermo-electric problem quite challenging and, as said, unseen within the usual thermal analyzes in the space industry.

The use of an explicit method for the solar panels modeling might represent an alternative and simpler way for the electric model, in relation to the 1-Diode/2-Resistor equivalent circuit model [30]. This seems reasonable in the present cases, bearing in mind that a detailed modeling of the electrical problem is not essential. The approach proposed by Pindado and Cubas [17], manages to address both issues in a simple way and with a high degree of accuracy. It involves an explicit formulation that depends on the photovoltaic device manufacturer datasheet parameters $\left(I_{s c}\right.$ the short-circuit current, $I_{m p}$ the maximum power current, $V_{o c}$ open-circuit voltage, and $V_{m p}$ maximum power voltage), thus greatly simplifying the calculation problem. Two different equations, one for $V<V_{m p}$ and a second one for $V>V_{m p}$, are defined to describe the solar cell/panel 
TABLE II

Characteristic Values of the Azur Space Triple Junction 3G28C Solar Cell and the Selex-Galileo SPVS 5-cell

\begin{tabular}{lccc}
\hline \hline Parameter & Symbol & $\begin{array}{c}3 \mathrm{G} 28 \mathrm{C} \\
\text { solar cell }\end{array}$ & $\begin{array}{c}\text { Selex- } \\
\text { Galileo } \\
\text { SPVS-5 }\end{array}$ \\
\hline Area $\left[\mathrm{cm}^{2}\right.$ ] & $A_{c}$ & 30.18 & 150.9 \\
\hline Open Circuit Voltage [V] & $V_{o c}$ & 2.667 & 13.335 \\
\hline Short Circuit Current [A] & $I_{s c}$ & 0.506 & 0.506 \\
\hline Voltage at max. Power [V] & $V_{m p}$ & 2.371 & 11.855 \\
\hline Current at max. Power [A] & $I_{m p}$ & 0.487 & 0.487 \\
\hline $\begin{array}{l}\text { Open Circuit Voltage Thermal } \\
\left.\text { coefficient [mV/ } /{ }^{\circ} \mathrm{C}\right]\end{array}$ & $\alpha_{V o c}$ & -6.0 & -30.0 \\
\hline $\begin{array}{l}\text { Short Circuit Current Thermal } \\
\left.\text { coefficient [mA } /{ }^{\circ} \mathrm{C}\right]\end{array}$ & $\alpha_{I s c}$ & 0.32 & 0.32 \\
\hline $\begin{array}{l}\text { Voltage at max. Power Thermal } \\
\left.\text { coefficient [mV } /{ }^{\circ} \mathrm{C}\right]\end{array}$ & $\alpha_{V m p}$ & -6.1 & -30.5 \\
\hline $\begin{array}{l}\text { Current at max. Power Thermal } \\
\text { coefficient }\left[\mathrm{mA} /{ }^{\circ} \mathrm{C}\right]\end{array}$ & $\alpha_{I m p}$ & 0.28 & 0.28 \\
\hline \hline
\end{tabular}

Nominal Values Obtained at STC, That Is AM0, $G=1367 \mathrm{~W} / \mathrm{m}^{2}$, and $T=28{ }^{\circ} \mathrm{C}$ (Beginning of Life-BOL-Values)

behavior (that is, the $I-V$ curve):

$$
I=\left\{\begin{array}{l}
I_{s c}\left[1-\left(1-\frac{I_{m p}}{I_{s c}}\right)\left(\frac{V}{V_{m p}}\right)^{\left.\frac{I_{m p}}{I_{s c}-I_{m p}}\right] ; V \leq V_{m p}}\right. \\
I_{m p} \frac{V_{m p}}{V}\left[1-\left(\frac{V-V_{m p}}{V_{o c}-V_{m p}}\right)^{\phi}\right] ; V \geq V_{m p}
\end{array} .\right.
$$

In the above equation, the exponent $\phi$ can be defined as:

$$
\begin{aligned}
\phi & =-\left.\frac{\partial I}{\partial V}\right|_{V=V_{o c}} \frac{V_{o c}}{I_{m p}}\left(\frac{V_{o c}}{V_{m p}}-1\right) \\
& \simeq \frac{I_{s c}}{I_{m p}}\left(\frac{I_{s c}}{I_{s c}-I_{m p}}\right)\left(\frac{V_{o c}-V_{m p}}{V_{o c}}\right) .
\end{aligned}
$$

The effect of solar irradiance $G$, and solar cells temperature $T$, on the panel behavior (that is, on the $I-V$ curve), can be taken into account by addressing the dependence of the four characteristic points with $G$ and $T$. This information is typically included in the datasheet of the solar cells/panels from the manufacturer, and it can be generally expressed as [31]-[33]:

$$
\begin{aligned}
I_{s c} & =\frac{G}{G_{0}}\left[I_{s c 0}+\alpha_{I s c}\left(T-T_{0}\right)\right], \\
I_{m p} & =\frac{G}{G_{0}}\left[I_{m p 0}+\alpha_{I m p}\left(T-T_{0}\right)\right], \\
V_{o c} & =V_{o c 0}+a V_{T} \ln \frac{G}{G_{0}}+\alpha_{V o c}\left(T-T_{0}\right), \\
V_{m p} & =V_{m p 0}+a V_{T} \ln \frac{G}{G_{0}}+\alpha_{V m p}\left(T-T_{0}\right),
\end{aligned}
$$

being $\alpha_{I s c}, \alpha_{I m p}, \alpha_{V o c}$, and $\alpha_{V m p}$ the coefficients that define the variation of the corresponding parameter with the temperature $T$, in relation to the reference one $T_{0}$. As an example, the coefficients of the Azur Space triple junction 3G28C solar cells, measured at standard test conditions (STC), are included in Table II. These are the solar cells used in the Selex-Galileo SPVS 5-cell (series connected) modules (see Fig. 1), that conform each one of the five
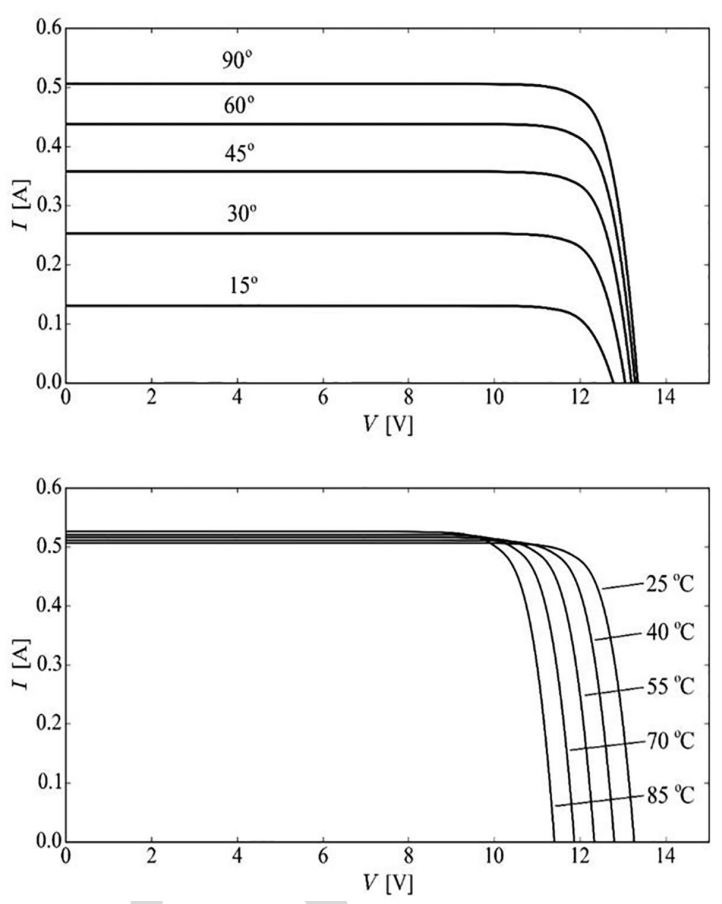

Fig. 4. $I-V$ curves of Selex-Galileo SPVS 5-cell modules (see also Fig. 1 and Table II) plotted for different incident angles $\alpha$, of the irradiance (top), and for different temperatures (bottom).

solar panels of the UPMSat-2 (the coefficients related to these modules are also included in Table II).

The results from Table II were checked at the facilities of CIEMAT (Centro de Investigaciones Energéticas, Medioambientales y Tecnológicas, the public research body devoted to energy and environment and the technologies related to them in Spain [34]-[36]), by measuring the $I-V$ curve of one SPVS five solar modules.

In Fig. 4, the effect of the variation of the irradiance $G$, on the $I-V$ curve is shown. Since the typical source of variation of $G$ in space is the direction of the sunlight in relation to the solar panels, the curves have been plotted for different values of the angle between the irradiance direction and the surface of the solar panel $\theta$, (for each curve, the associated irradiance can be obtained as $1367 \mathrm{~W} / \mathrm{m}^{2}$ multiplied by $\sin \theta$ ). Additionally, the effect of the temperature $T$, on the solar panel $I-V$ curve is shown in the aforementioned figure. Five different curves, corresponding to temperatures between $25^{\circ} \mathrm{C}$ and $85^{\circ} \mathrm{C}$, have been plotted in this graph. All curves of Fig. 4 were calculated with (2).

In order to obtain the power delivered by a solar panel $P$, it is necessary to know the admittance of the system to which the panel is connected. This information gives the operation point on the $I-V$ curve, and hence the power supplied by the panel $(P=V I)$. Due to this reason, this operation point might be essential in the design of a spacecraft power subsystem. As it can be seen in the rightmost part of the $I-V$ curves from Fig. 4, slight variations in the output voltage $V$, can produce important variations in power due to the steep slope of the curves in that region. Furthermore, the 


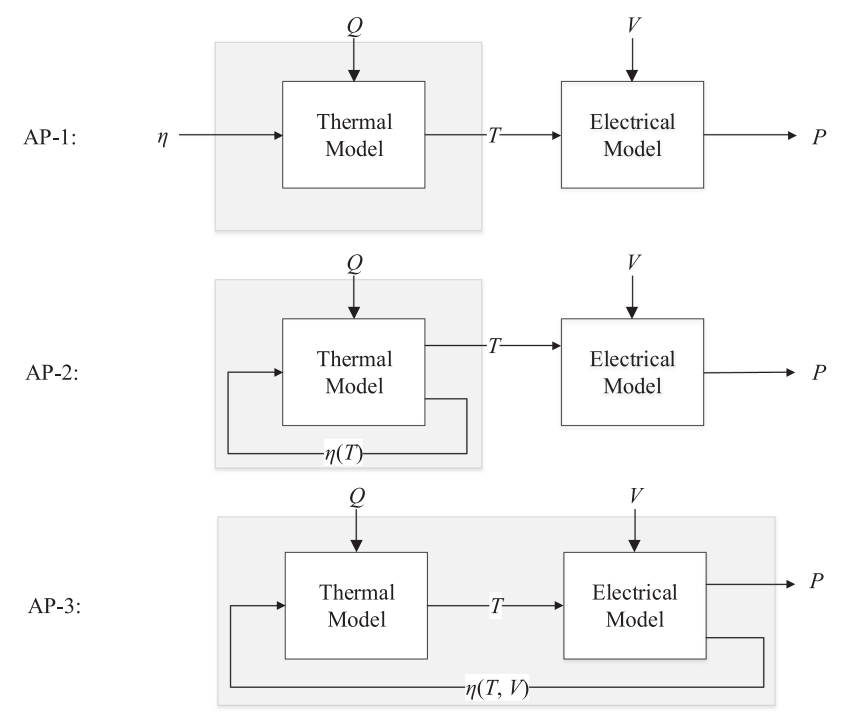

Fig. 5. Typical thermo-electrical methodologies used in thermal analysis. In each case, the part of the problem implemented in the thermal software used for the present analysis is indicated by grey background.

possible combinations of temperature $T$, and output voltage $V$, should be carefully considered, as certain values of the output voltage can maximize the delivered power, but the same values of this voltage may not produce power at all if the temperature of the cells rises. For example, a value of $V=12.3 \mathrm{~V}$ produces the maximum possible amount of power at $25^{\circ} \mathrm{C}$, but the current $I$ and thus the power $P$ fall to zero for $T>55^{\circ} \mathrm{C}$. It is therefore important to consider all these factors when analyzing the power provided by the solar panels.

\section{B. Thermo-Electric Problem}

Three different approaches/levels of complexity can be considered in the thermo-electric problem (see Fig. 5):

1) In the first approach, hereinafter AP-1, for each time step, the thermal and power mathematical models are calculated as sequential independent problems. This approach is still quite common in preliminary analyses. For the thermal problem, the efficiency of the panels $\eta$, is a constant, and in the case of the electrical problem, the temperature of the panels $T$, is indicated by the thermal problem.

2) In the second approach, hereinafter AP-2, the thermo-electric problem is coupled but only from the thermal point of view. This is the approach currently used for detailed thermal analysis. For each time step, the thermal problem is solved first considering the effect of temperature on the photovoltaic efficiency $\eta$. The electrical problem is ignored by assuming that the solar panel is continuously working with an MPPT, that is, the photovoltaic panel voltage $V$, is assumed to be equal to the maximum power voltage $V_{m p}$ [3]. Therefore, the efficiency of the panel only depends on the temperature. Within this approach any variation in the panel temperature shall produce a variation in the panel efficiency $\eta$, which in turn affects the amount of heat $Q_{S}$, absorbed by the panel [37]. This leads to an iteration process until an equilibrium solution is reached. After the thermal problem, the electric problem and the temperature effects on the power production $P$, are solved using the temperature outputs of this thermal analysis as an input in the electrical model. The problem with this approach is that it is only realistic when the operating voltage of the panels is controlled, something that is not implemented in most small satellites.

3) In the present article, a third approach to the thermal problem of DET satellites, hereinafter AP-3, is presented. In this case, the thermal and the electric models are coupled. That is, both are solved at the same time in each time step inside the thermal analysis software. Within this approach, both variations in the panel temperature and panel voltage produce variations in the panel efficiency $\eta$, which in turn affects the amount of heat $Q_{S}$, absorbed by the panel. And, again, this leads to an iteration process until an equilibrium solution is reached. It should be pointed out that the variation in efficiency produced at a defined temperature is determined by the admittance $I / V$, to which the solar panel is connected. This admittance provides the corresponding point on the $I-V$ curve, which is defined for a single temperature $T$. This approach is essential for representing the DET configuration of satellite power subsystems, the battery being directly connected to the solar panels. It is a simple design that, although it does not maximize the power delivery from the solar panels, reduces the possibility of failure as less electronic circuits are involved.

\section{RESULTS}

\section{A. Thermo-Electric Problem of a Simple Solar Panel}

In order to carry out a first comparison between the three approaches described above, a simple case has been proposed: one solar panel in space, facing the Sun and orbiting Earth in a polar orbit whose plane is parallel to the solar irradiance (see Fig. 6). The thermo-electric models have been built in ESATAN ${ }^{\circledR}$. The solar panel is composed of one single Selex-Galileo SPVS 5-cell module (see Fig. 1 and Table II).

The thermo-electric model has been built by using a very simple 2-node thermal model as a base, the cells of the solar panel being grouped into one single thermal node with uniform temperature (node \#1), using the lumped parameter approach [38], [39]. The second node is used to model the substrate (node \#2). In Fig. 6 (bottom), the node for the solar panels is depicted in grey color, whereas the substrate is depicted in white. The main radiative heat fluxes are shown on the left side of the figure: direct solar flux $\left(Q_{S}\right)$, reflected albedo $\left(Q_{A}\right)$, and infrared radiation from Earth $\left(Q_{E}\right)$. The mathematical model that describes this problem 


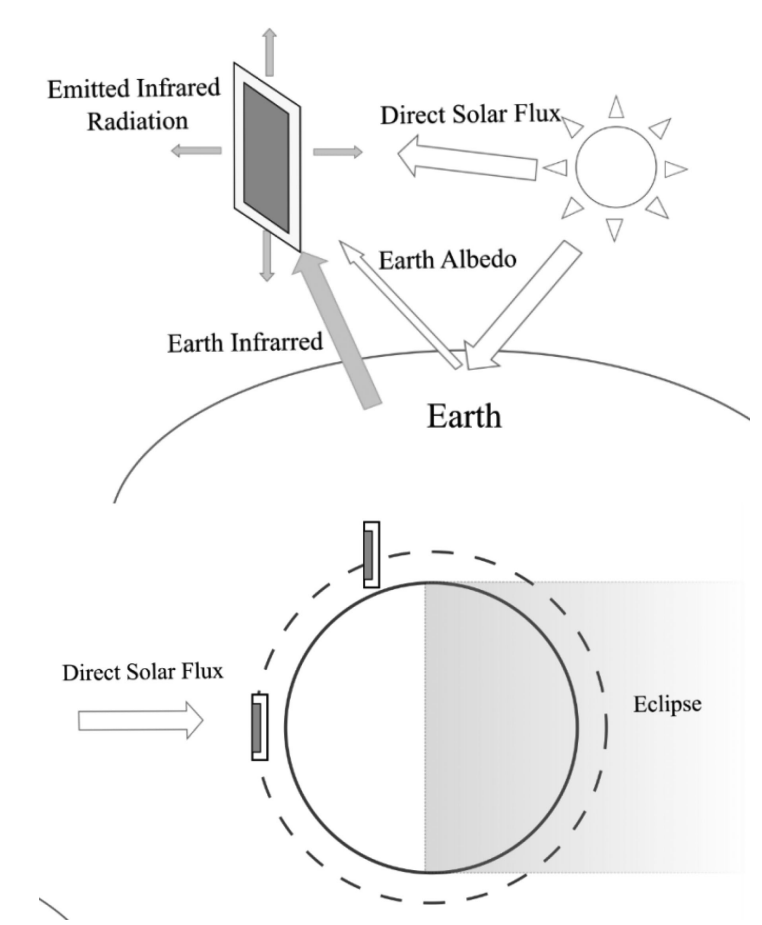

Fig. 6. Simple case study analyzed to compare the three approaches of the thermo-electric problem. Sketches of the main heat fluxes of thermal model (top), and the considered orbit (bottom).

is the following one:

$$
\begin{aligned}
C_{1} \frac{\mathrm{d} T_{1}}{\mathrm{~d} t}= & Q_{S-1}+Q_{A-1}+Q_{E-1}+G L_{12}\left(T_{2}-T_{1}\right), \\
& -\sigma G R_{1 E} T_{1}^{4}+\sigma G R_{1 \infty}\left(T_{\infty}^{4}-T_{1}^{4}\right), \\
C_{2} \frac{\mathrm{d} T_{2}}{\mathrm{~d} t}= & Q_{S-2}+Q_{A-2}+Q_{E-2}+G L_{12}\left(T_{1}-T_{2}\right), \\
& -\sigma G R_{2 E} T_{2}^{4}+\sigma G R_{2 \infty}\left(T_{\infty}^{4}-T_{2}^{4}\right),
\end{aligned}
$$

where for each one of the nodes (subscript 1 or 2), the variation of the internal energy $\left(C_{i} \mathrm{~d} T_{i} / \mathrm{d} t\right)$ is equal to the sum of external heat fluxes $\left(Q_{S}, Q_{A}, Q_{E}\right)$, plus the conductive heat exchange with the other node of the photovoltaic device $(G L$ term), minus the infrared heat load radiated to Earth $\left(\sigma G R_{i E} T^{4}\right)$ plus the heat exchanged by radiation with deep space $\left(\sigma G R_{i \infty}\left(T_{\infty}{ }^{4}-T^{4}\right)\right)$, at a temperature of $T_{\infty}=3 \mathrm{~K}$. In this case, the desired solution is the cyclic periodic solution, in which the thermal problem is solved iteratively, introducing the solution of the final point of one orbit as the initial conditions of the following. The problem is considered solved when the differences between the solutions of two consecutive orbits were below $0.01 \mathrm{~K}$.

The radiative external loads $\left(Q_{S}, Q_{A}, Q_{E}\right)$ and the radiative heat exchange coefficients $(G R)$ were calculated by ESATAN $^{\odot}$ using a Monte Carlo ray tracing algorithm. However, the solar heat loads actually absorbed as heat by the solar cell $Q_{S-1}$ and $Q_{A-1}$ depend on the cell's efficiency and reflectivity. These absorbed heat loads are the fraction of the solar irradiance arriving to the cell that is not converted into electric power nor reflected to space. The efficiency $\eta$ dictates the amount of energy transformed into electric power by the photovoltaic device. As for the reflected
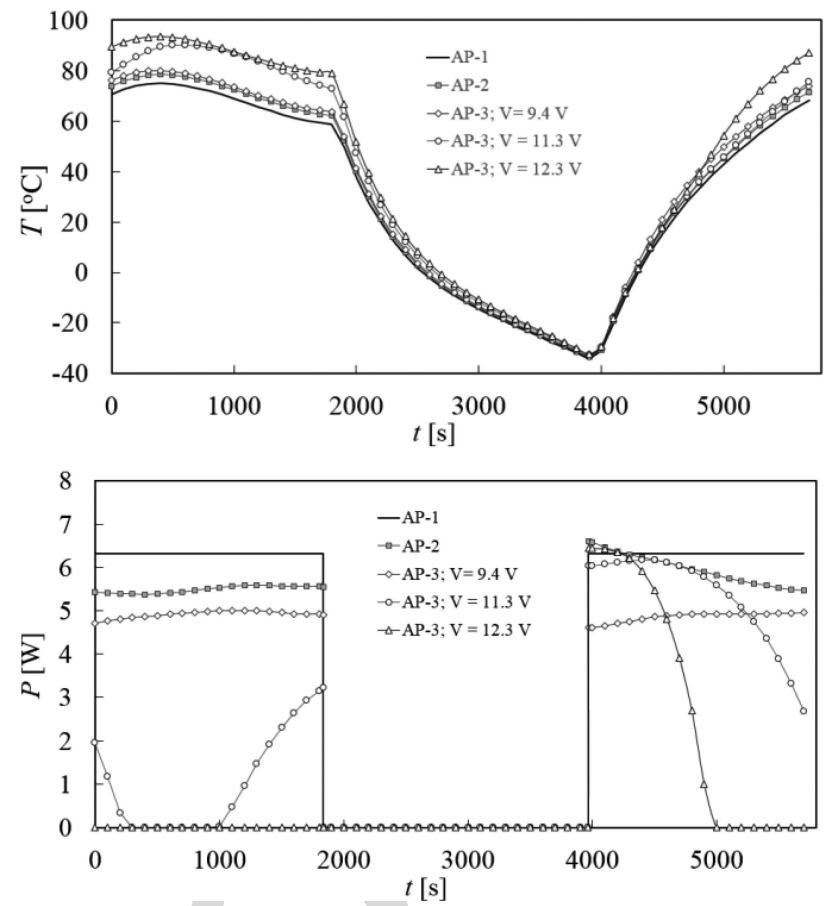

Fig. 7. Results from the simple case analyzed [solar panel formed by a Selex-Galileo SPVS 5-cell module facing the sun during one orbit (see Fig. 6)]. Cells temperature (top) $T$, and power delivered by the solar panel (bottom) $P$, along one orbit. The results from the different approaches followed to model the electric operation of the panel (AP-1, AP-2, and AP-3 -with the three selected output voltages-), are included in the graphs.

solar irradiance, it depends on the cells solar reflectance $\rho$. In thermal control, it is typical to work with the solar absorptance instead, $\alpha$ which for an opaque material is $\alpha=$ $1-\rho$. Therefore, the solar heat loads absorbed by the solar cell can be defined as

$$
\begin{aligned}
& Q_{S-1}=Q_{S-1}^{*} \alpha_{e f f}=Q_{S-1}^{*}(\alpha-\eta) \\
& Q_{A-1}=Q_{A-1}^{*} \alpha_{e f f}=Q_{A-1}^{*}(\alpha-\eta) .
\end{aligned}
$$

In the above equations, the values of the solar heat loads absorbed by the solar cell $Q_{S-1}$ and $Q_{A-1}$, equal the values obtained by ESATAN $^{\odot}$ (calculated using a solar absorptance of $\alpha=1$-symbols with a star (*) superscript, $Q^{*}{ }_{S-1}$ and $Q^{*}{ }_{A-1}$ ), multiplied by the effective solar absorptance $\alpha_{\text {eff. }}$. This effective solar absorptance is obtained by subtracting the cells efficiency $\eta$, to the actual solar absorptance $\alpha$. As the cells are triple junction cells and produce energy from all the solar wavelength [40], albedo has been considered as a source of energy as well. Therefore, in expressions (4)-(7), $G=Q^{*}{ }_{S}+Q^{*}{ }_{A}$. However, this may be studied from case to case.

This simple case has been solved with the three different approaches described above: AP-1, AP-2, and AP-3 (see Fig. 7 and Table III). The main difference between them is the mode of calculating the efficiency of the solar panel $\eta=I V / A G$. In the first approach AP- $1, \eta$ is considered constant, equal to the maximum efficiency value $\left(\eta_{\max }=\right.$ 0.28). In the second approach AP- $2, \eta$ is not constant but the panel is working at the MPP, that is, $V=V_{m p}$, and $I=$ 
TABLE III

Results From the Simple Case Analyzed (Solar Panel Formed by a Selex-Galileo SPVS 5-cell Module Facing the Sun During One Orbit, See Fig. 1)

\begin{tabular}{lccc}
\hline \hline Thermo-electric approach & $T_{\max }\left[{ }^{\circ} \mathrm{C}\right]$ & $T_{\min }\left[{ }^{\circ} \mathrm{C}\right]$ & $P_{\text {mean }}[\mathrm{W}]$ \\
\hline AP-1 & 75.0 & -35.4 & 4.0 \\
\hline $\mathrm{AP}-2$ & 78.4 & -34.8 & 3.6 \\
\hline $\mathrm{AP}-3(V=9.4 \mathrm{~V})$ & 80.0 & -34.8 & 3.1 \\
\hline $\mathrm{AP}-3(V=11.3 \mathrm{~V})$ & 90.3 & -34.1 & 2.0 \\
\hline $\mathrm{AP}-3(V=12.3 \mathrm{~V})$ & 93.6 & -33.6 & 0.8 \\
\hline \hline
\end{tabular}

Maximum and Minimum Temperature Values of the Solar Panel, and Mean Value of the Power Delivered, for the Analyzed Cases.

$I_{m p}$. Therefore, only (5) are used to obtain voltage $V_{m p}$, and current $I_{m p}$, for each temperature, and then the efficiency $\eta(T)$, is obtained by using those values. With this new value of the efficiency a new value of the temperature can be generated for the next iteration, the process being repeated until convergence is achieved. In the approach proposed in this work (AP-3), the admittance to which the solar panel is connected $I / V$, is taken into account by considering three different solar panel output voltage values: 9.4, 11.3, and $12.3 \mathrm{~V}$ (corresponding to minimum, nominal and maximum expected voltages during the mission). With the value of the voltage fixed, the current can be calculated for certain values of irradiance and temperature (3)-(7). After that, it is possible to calculate the produced power $P$, and the efficiency $\eta$. Again, with this new value of the efficiency, a new value of the temperature can be generated for the next iteration, the process being repeated until convergence is achieved. The selected values of the solar panel output voltage values are derived from the limits of the operational voltage range of the UPMSat-2 mission, plus an intermediate value corresponding to $V_{m p}$ at nominal temperature $\left(T=28{ }^{\circ} \mathrm{C}\right)$.

In Fig. 7, the evolution of solar panel temperature $T$, within one orbit is plotted in relation to the time $t$, whereas the power $P$, delivered by the solar panel is plotted in the bottom graph. AP-1 provides the lowest temperature profile and a constant power output of $6.3 \mathrm{~W}$ during solar illumination, which occurs constantly outside the eclipse period $(t=1840 \mathrm{~s}$ to $t=3960 \mathrm{~s}$ ). As the efficiency remains constant (with the larger value from the STC, $\eta=28 \%$ ), the amount of energy transformed into heat is lowest, thus resulting in the lowest temperatures as well. The results corresponding to AP-2 (working under the hypothesis that the voltage $V$ is always fixed at the MPP for each temperature), show a slightly higher temperature (around $2.5^{\circ} \mathrm{C}$ for the warmest points of the orbit), and a power output that reflects the loss of efficiency even with a theoretically perfect MPPT. The power obtained by AP- 2 is lower than the power obtained by AP-1, with the exception of a small period after the eclipse, in which the efficiency of the solar panel is larger than the maximum from STC. The efficiency of AP-1 could have increased in the case of having chosen an efficiency that was constant but closer to the one corresponding to the average temperature of the satellite during orbit.
The results obtained by using AP-3 require a more thorough explanation. The results related to the first selected voltage $(V=9.4 \mathrm{~V})$ show a higher temperature of the solar panel, resulting in a lower amount of power delivered by the solar panel when compared to AP-1 or AP-2. With regard to the second selected voltage $(V=11.3 \mathrm{~V})$, the temperature rises at the initial period of the orbit, causing a decrease of the power delivered to zero. However, the temperature of the solar panel decreases before the eclipse after reaching its maximum, resulting in some power delivery by the solar panel. After the eclipse, the temperature of the solar panel starts rising from its minimum value which, on the other hand, causes the decrease of the power delivered from its maximum (just after the eclipse). The results obtained with the third selected voltage $(V=12.3 \mathrm{~V})$ are similar to the ones from the previous case $(V=11.3 \mathrm{~V})$, but now the solar panel delivers power during a brief period after the eclipse (in which the low temperatures modify the shape of the solar panel's $I-V$ curve, setting its open circuit voltage above the selected voltage level).

The results of this simulation are summarized in Table III. As it can be observed, the differences between the modeling approaches may derive in a maximum predicted temperature divergence larger than the typical temperature uncertainty margins $\left( \pm 10^{\circ} \mathrm{C}\right)$, resulting in noticeable differences regarding the power delivered by the solar panel.

\section{B. Thermo-Electric Analysis of the UPMSat-2}

In this section, the power production in a real mission is analyzed in detail by using the thermo-electric modeling (AP-3) described above, in order to demonstrate the important variations that can be obtained in thermal and electrical results depending on the voltage variation of a DET satellite: the UPMSat-2, see Section I for relevant characteristics of this spacecraft.

The attitude control system is magnetic and spin stabilized. It is based on providing a magnetic torque following the control law:

$$
\vec{m}=-k\left(\vec{b}+\vec{\omega}_{d} \times \vec{b}\right)
$$

where $\vec{b}$ is Earth's magnetic field at the satellite's position, $\vec{\omega}_{d}$ is the intended angular velocity, and $k$ is an adjustable constant. This magnetic control law has been demonstrated to be stable and robust, and after some initial detumbling, the angular velocity of the satellite converges to $\vec{\omega}=\vec{\omega}_{d}$ [41]. According to this control law, the axis of rotation of the satellite $(Z)$ is orthogonal to the local magnetic field. The satellite with its reference coordinate system can be observed in Fig. 8. The satellite's attitude along the orbit in the orbital reference frame $\left(X_{0}, Y_{0}, Z_{0}\right)$, can be observed on the right side of the figure. In this reference frame, $X_{0}$ axis points toward the ascending node of the orbit, $Y_{0}$ is perpendicular to the orbit pointing toward the negative direction of the satellite's rotation axis, and $Z_{0}$ coincides with Earth's axis of rotation.

The power subsystem relies on photovoltaic solar cells for power generation and on an $18 \mathrm{~A} \cdot \mathrm{h}$ Li-ion battery. The 

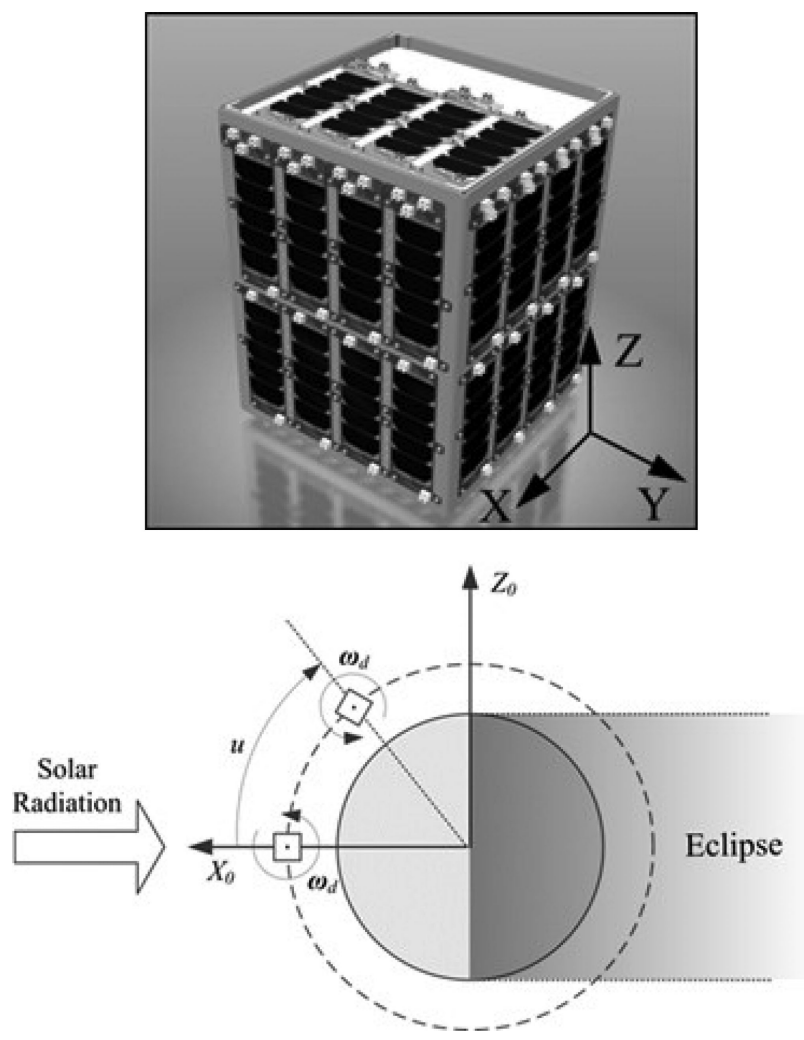

Fig. 8. UPMSat-2 coordinates system (top). Sketch of the UPMSat-2 normal attitude within the selected orbit, rotating around its $Z$-axis (bottom).
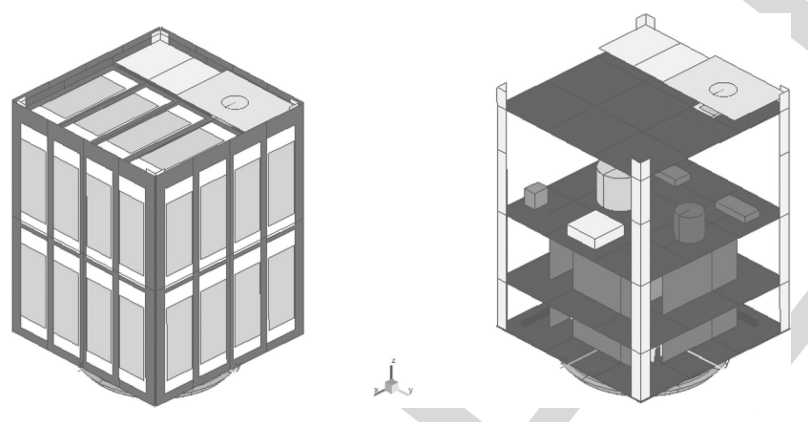

Fig. 9. Sketch of the UPMSat-2 ESATAN ${ }^{\odot}$ thermal mathematical model.

solar panels of the satellite are built with Selex-Galileo SPVS 5 modules. The solar panels allocated on the four lateral faces of the satellite $(-\mathrm{X},-\mathrm{Y},+\mathrm{X},+\mathrm{Y})$, are built with four pairs of modules connected in parallel (these pairs of modules are composed of two modules connected in series). There is a fifth solar panel, located on the top face $(+Z)$, that will provide some power supply in certain moments of the mission.

The thermo-electric model has been developed using as a base the UPMSat-2 thermal model within the UPMSat2/VEGA launcher coupled thermal analysis, required by the launcher authority [42] (see Fig. 9). This model had been correlated with the thermal vacuum test data previously to delivery to Arianespace. It is composed of 383 nodes, being a small-to-medium thermal model. The solar modules of the panel are identical to the one that was modeled in the previous section, that is, all solar cells are supposed to be merged into one. The electrical behavior of the UPMSat-2 solar panels was studied by modeling the $I-V$ curve of solar module with (2)-(7).

As the battery voltage of the UPMsat-2 sets the working point of the solar panels on the $I-V$ curve, three different voltage levels have been considered, the minimum and the maximum battery voltages, and an intermediate value (that is, 18.8, 22.6, and 24.6 V). The delivered power from each one of the Selex-Galileo SPVS 5 modules was obtained from its $I-V$ curve, considering a voltage level equal to half the solar panel output voltage (as in the UPMSat-2 solar panels, the modules are grouped in pairs connected in series).

Three main different configurations of the satellite's attitude have been studied.

1) Case 1: no rotation (that is, $\omega_{d}=0$ ), $+X$ face always pointing to the Sun along the orbit (see Figs. 8-9).

2) Case 2: no rotation, $+X+Y$ diagonal always pointing to the Sun along the orbit.

3) Case 3: nominal rotation rate, $\omega_{d}=90$ rotations per orbit. Besides, two more rotation rates were analyzed: Case $3 \mathrm{a} \omega_{d}=10$ and Case $3 \mathrm{~b} \omega_{d}=5$ rotations per orbit.

The temperature results related to Cases 1 to 3 are included in Fig. 10. In the graphs, the solar cell temperatures for panels $+\mathrm{X}$ and $+\mathrm{Y}$, together with the temperatures of the satellite's Tray A (which has been selected as an example of the inner temperature of the satellite), are plotted versus time along one orbit, for the three selected output voltages. In Case 1 , the temperature of panel $+X$ has the greater variations, as it faces the Sun. On the other hand, panel $+\mathrm{Y}$ shows lower temperatures (as it faces deep space and does not receive any radiation from the Sun), with some variations due to the effects of albedo and the infrared fluxes. The main result to highlight is the temperature variation of panel $+\mathrm{X}$ in relation to the output voltage. For output voltages $V=18.8 \mathrm{~V}$ and $V=22.6 \mathrm{~V}$ the temperature of panel $+\mathrm{X}$ are the basically the same. However, the higher voltage, $V=24.6 \mathrm{~V}$, implies larger temperatures (with maximum differences of more than $10^{\circ} \mathrm{C}$ ), indicating a decrease of the photovoltaic power supply. In Case 2, panel $+\mathrm{Y}$ temperature shows a similar pattern to the one from $+\mathrm{X}$ panel, as in this case this panel receives the Sun irradiance. In Case 3, the temperatures of panels $+\mathrm{X}$ and $+\mathrm{Y}$ are somehow between the temperatures of both panels in Case 1, oscillating around an average value in each instant of the orbit as the satellite is rotating now around $+\mathrm{Z}$.

The electric power supply from all lateral panels $(+X$, $+\mathrm{Y},-\mathrm{X}$, and $-\mathrm{Y}$ ) is shown in Fig. 11, in relation to the instant position along the satellite's orbit for the analyzed Cases 1 to 3. The power production is clearly affected by the area exposed to the Sun irradiance: the production in Case 2 is larger than in Case 1; but also by the output voltage, as in both cases a $24.6 \mathrm{~V}$ voltage level implies a reduction of the supplied power when the temperature rises after the 

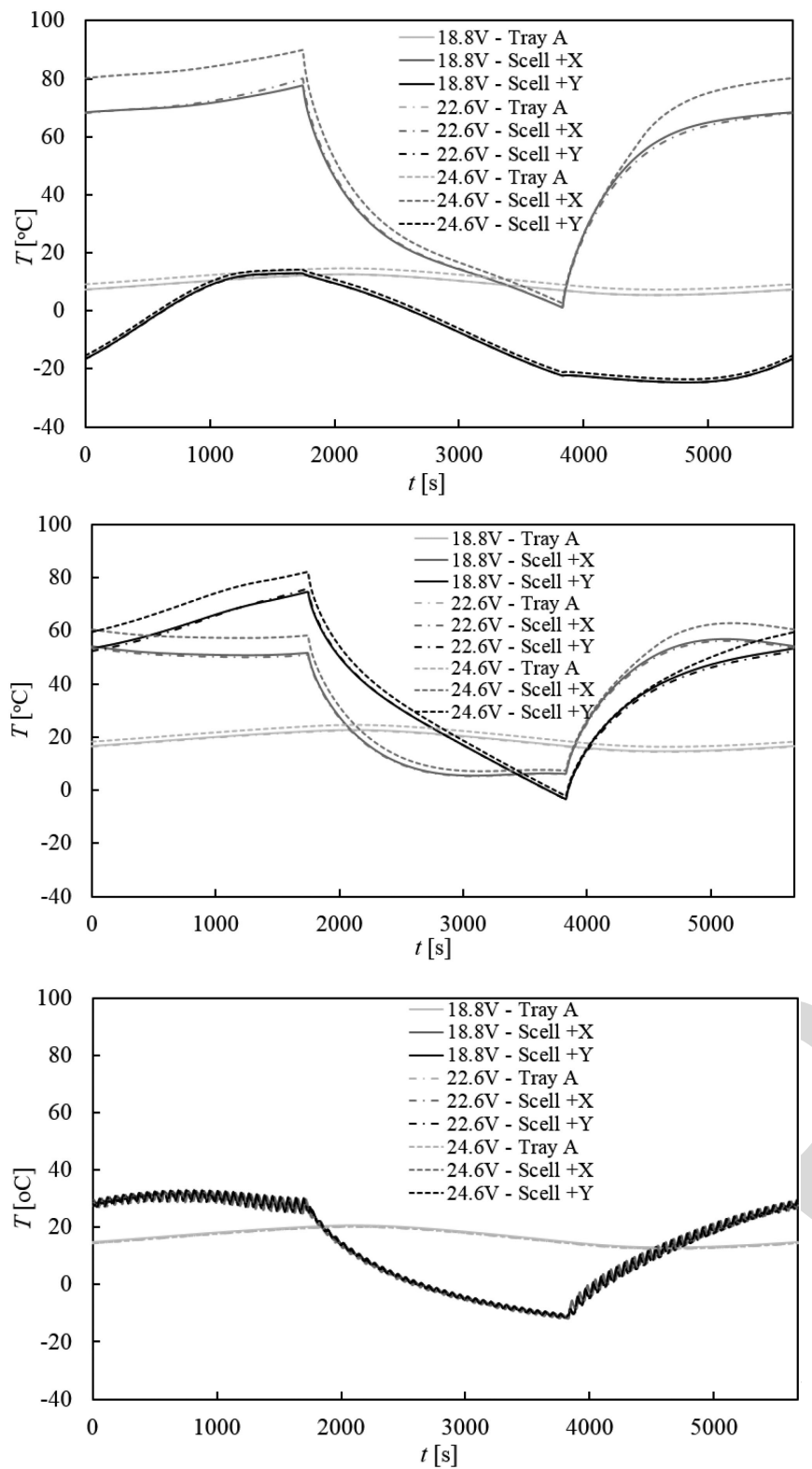

Fig. 10. Temperature results for Tray A (light grey), $+\mathrm{X}$ solar panel (grey), and + Y solar panel (black) using AP-3 thermo-electric model for three selected output voltages: $18.8 \mathrm{~V}$ (continuous line), $22.6 \mathrm{~V}$ (dashed-dotted line), and 24.6 V (dotted line). Top figure is for Case 1, middle figure for Case 2 and figure below is for Case 3 .

eclipse. Nevertheless, the photovoltaic supplied power rises to $20 \mathrm{~W}$ in Case 1 once the minimum after the eclipse is reached, this increase being due to the albedo radiation on panels $+\mathrm{Y},-\mathrm{X}$, and $-\mathrm{Y}$, which do not receive any irradiance from the Sun. In Case 3, the power supply oscillates due to the rotation of the satellite, each panel being alternatively irradiated. In this case, the power is almost not reduced for the larger voltage level, as the temperature of the panels remains below $30{ }^{\circ} \mathrm{C}$.

\section{DISCUSSION}

The main result of the thermoelectric analysis described in this section is to conclude that the UPMSat-2 satellite has an adequate design. The attitude control with which
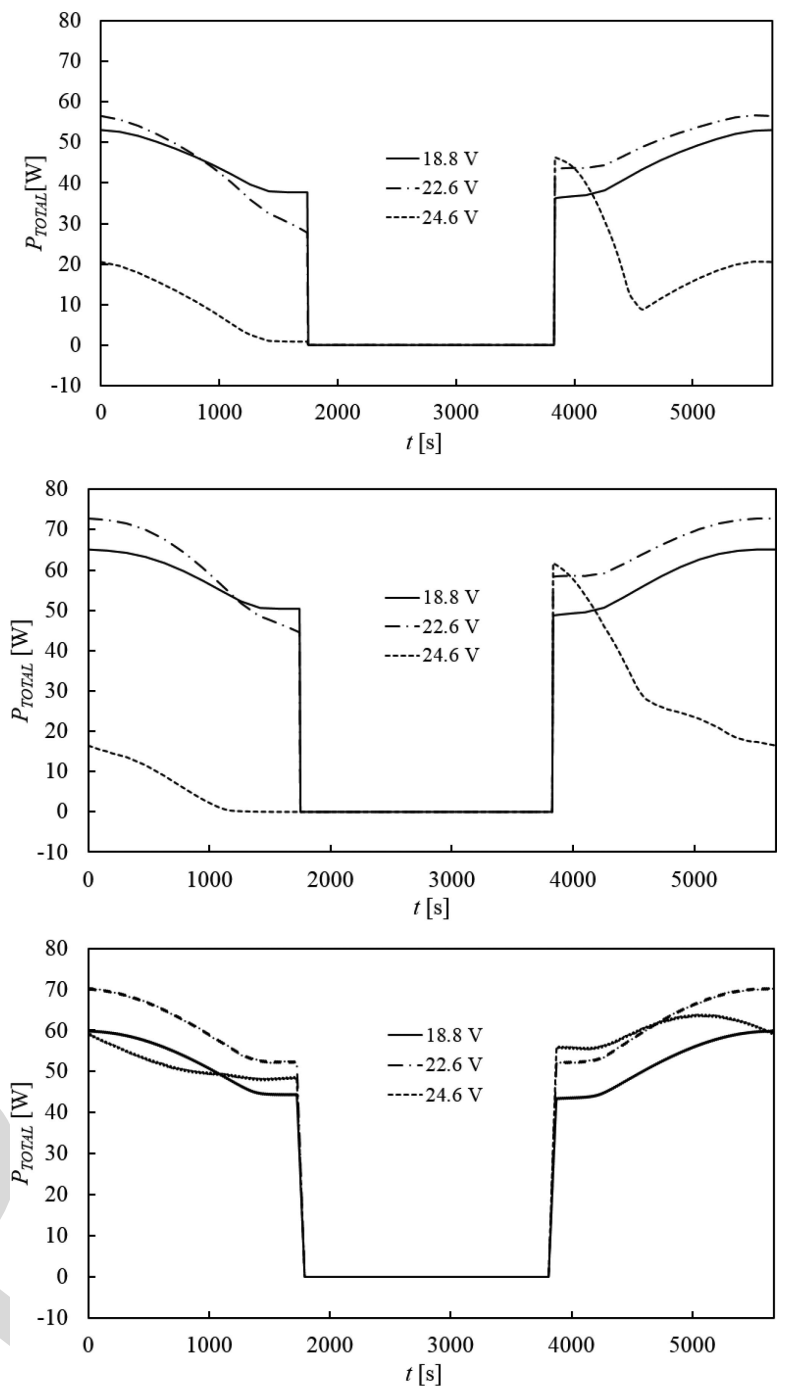

Fig. 11. Total produced power orbital results for the UPMSat-2 using AP-3 thermo-electric model for three selected output voltages: $18.8 \mathrm{~V}$ (continuous line), $22.6 \mathrm{~V}$ (dashed-dotted line), and $24.6 \mathrm{~V}$ (dotted line). Top figure is for Case 1, middle figure for Case 2, and figure below is for Case 3.

the satellite will operate corresponds to Case 3, which allows power production with the higher battery voltage level $V=24.6 \mathrm{~V}$ (see Fig. 12). It should be also said that although in Case 2 the satellite exposes more solar panel's area to the Sun (and the maximum power production is reached for certain output voltages), power production is not guaranteed for high output voltages (since the high temperatures reached by the solar panels in some parts of the orbit will decrease the power production).

Case 1 and Case 2 will not occur for UPMSat- 2 due to its attitude control. However, they could have happened if a three-axis stabilization had been chosen. Those situations would seriously limit the power production taking into account the operation voltage limits of the battery. On the other hand, it could be objected that a low power production in the case of a high battery voltage is not an important problem, since the low amount of energy produced by the panels would lead to a discharge of the battery, which would lower its voltage, increasing the power production 


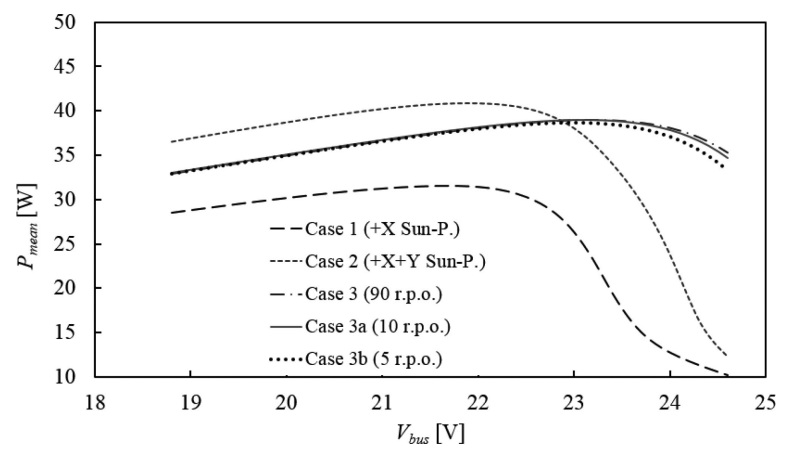

Fig. 12. Mean generated power per full orbit for five different UPMSat-2 attitudes: $+X$ solar panel oriented toward the Sun (Case 1, dashed line), XY diagonal oriented toward the Sun (Case 2, densely dotted line), 90 revolutions per orbit rotation rate (Case 3, dashed-dotted line), 10 revolutions per orbit rotation rate (Case $3 \mathrm{a}$, continuous line), and 5 revolutions per orbit rotation rate (Case $3 b$, finely dotted line).

subsequently. Nevertheless, if a constant Sun-oriented attitude of the panels is required to charge them (as it usually is), and power predictions without using an appropriate thermo-electric model are used in order to manage operation times of the satellite, these predictions will most likely present substantial deviations; the batteries may not charge completely and the charging period will be longer than expected. Additionally, it should not be forgotten that the low production of the panels will lead to an increase in temperature, which may itself be a problem if the satellite is close to the operating limit, as this will decrease the solar panels lifetime. Also, lowering the battery voltage may not be an option if the battery is close to its limit or other electrical elements depend on a high voltage on the bus.

Bearing in mind the convenience of having a certain degree of rotation around the satellite $+\mathrm{Z}$ axis, two more cases were analyzed: Case $3 \mathrm{a}$ and Case $3 \mathrm{~b}$ with a reduced rotation rate of $\omega_{d}=10$ and $\omega_{d}=5$ rotations per orbit, respectively. The results have been plotted in Fig. 12. As it can be observed, even a low rotation rate keeps a power production far from a large decrease at high output voltage levels.

Finally, in Fig. 13, the temperature of the lateral solar panels of the UPMSat-2 ( $+\mathrm{Z}$ solar panel is not illuminated in normal mode attitude), and the current supplied by them during one of the communication intervals with Ground Control (GC). It can be observed that the temperature varies around $4{ }^{\circ} \mathrm{C}$ within the mentioned time interval ( 8 minutes). This information was obtained during the first week after the satellite's launch. The following two important conclusions can be derived from this figure:

1) The rotation rate of the satellite preserves the lateral solar panels at low temperatures (even when they are illuminated), which means that voltage levels at open circuit voltage and MPP have been displaced around $1.8 \mathrm{~V}$ from the nominal values (to $28.5^{\circ} \mathrm{C}$ and $25.5^{\circ} \mathrm{C}$, respectively). That implies that the battery voltage, whose maximum output voltage is $24.6 \mathrm{~V}$,
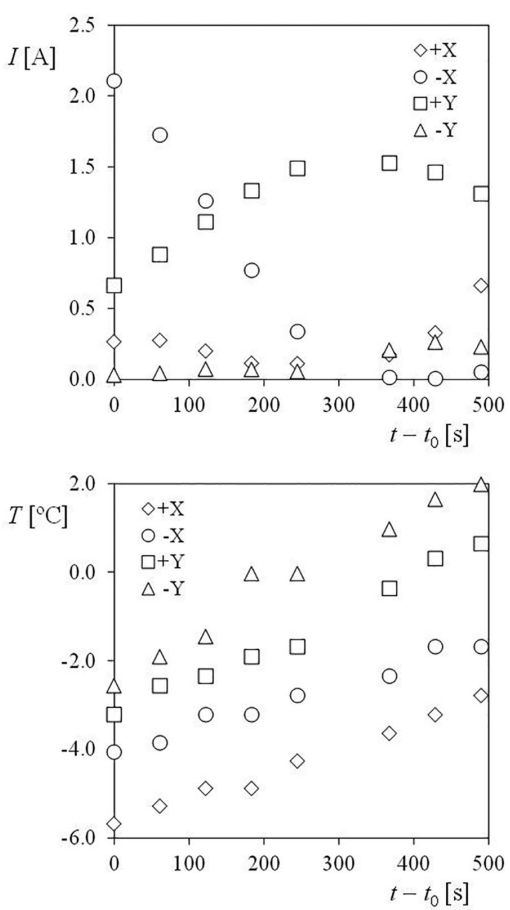

Fig. 13. Current $I$, (left) and temperature (right) $T$, from the UPMSat-2 lateral panels during the communications interval over GC. Measured on September 4, 2020.

will allow a continuous power flow from the solar panels.

2) However, if the rotation rate decreases and the temperature of the illuminated solar panels increases consequently, for high battery output voltage level the working point of the illuminated solar panels can be placed between maximum power and open voltage points. Taking into account the $8.2 \cdot 10^{-3}{ }^{\circ} \mathrm{C} \cdot \mathrm{s}^{-1}$ temperature variations observed during the communications interval and the work carried out with the SPVS 5 modules that form each solar panel [17], that represent a $1 \%$ loss of power delivery around the MPP in a 10-minutes interval (which turns into a $12 \%$ at the middle point between maximum power and open voltage points).

\section{CONCLUSION}

A new thermo-electrical modeling methodology for small satellites has been proposed and studied in the present work. This methodology comprises in a simple way the coupled analysis of the solar panels' temperature, their photovoltaic efficiency, and their output voltage. A simple but accurate explicit electric model of the solar panels was implemented, to relate the supplied current and the output voltage level, for different temperatures.

The results reveal a more accurate estimation of the power production when compared to other simpler approaches, which do not take into account the fall of 
the photovoltaic power production for large output voltage levels (close to the open circuit voltage).

Besides, the proposed thermo-electric modeling has been tested with the UPMSat-2 satellite mission, using the thermal model (carried out in $\operatorname{ESATAN}^{\odot}$ ), to analyze the effects on the power production and the temperatures distribution of three selected attitude modes of the satellite within its orbit.

In relation to the temperature, substantial variations have been obtained between the cases analyzed, sometimes above the typical margins in thermal design. Therefore, it can be concluded that in case of satellites with DET, the operating voltage in the thermal design cannot be ignored. The simulations carried out indicate a relevant effect of the battery voltage on the satellite's temperature.

From the power point of view, the simulations show that the method allows estimating the energy production of the satellite much more accurately and can help design the attitude control strategy.

Finally, the following tasks are planned as a logical extent of this article:

1) improve methodologies of thermo-electric modeling of nanosatellites within the NANOSTAR ${ }^{1}$ project;

2) improvement of the simulation by including the UPMSat-2 battery and DC-DC thermal effects;

3) improvement of the simulations by adding a sufficiently large thermal data package from the UPMSat2 mission.

\section{ACKNOWLEDGMENT}

The authors would like to thank Prof. Á. Sanz-Andrés for his constant support regarding the research program on spacecraft subsystems at Instituto Universitario de Microgravedad "Ignacio Da Riva" (IDR/UPM), from Universidad Politécnica de Madrid (UPM). Besides, the authors would like to thank the professors and staff from IDR/UPM, with special mention to Prof. G. Alonso, Prof. E. RoibasMillan, and Prof. J. Perez-Alvarez, for their work within the successful UPMSat-2 project. They would also like to thank L. Balenzategui, from CIEMAT, for his kind help with the SPVS $5 I-V$ curve testing campaign. The authors are also indebted to A. G. Maldonado for his kind help in reviewing the style of the text. Finally, they are grateful to the reviewers, whose suggestions helped to improve the present article.

\section{REFERENCES}

[1] E. Kulu Nanosats database 2019. [Online]. Available: https://www. nanosats. eu

\footnotetext{
${ }^{1}$ NANOSTAR is network of excellence between universities, the regional industry, and the scientific ecosystem in order to create a leading European platform on nanosatellites. https://nanostarproject.eu
}

[2] F. Davoli, C. Kourogiorgas, A. Panagopoulos, F. Patrone, and M. Marchese

Small satellites and CubeSats: Survey of structures, architectures, and protocols

Int. J. Satell. Commun. Netw., vol. 37, no. 4, pp. 343-359, 2018.

[3] M. R. Patel

Spacecraft Power Systems. Boca Raton, FL, USA: CRC Press, 2004.

[4] M. Veerachary, T. Senjyu, and K. Uezato

Voltage-based maximum power point tracking control of PV system

IEEE Trans. Aerosp. Electron. Syst., vol. 38, no. 1, pp. 262-270, Jan. 2002.

[5] R. Leyva, C. Alonso, I. Queinnec, A. Cid-Pastor, D. Lagrange, and L. Martínez-Salamero

MPPT of photovoltaic systems using extremum - seeking control

IEEE Trans. Aerosp. Electron. Syst., vol. 42, no. 1, pp. 249-258, Jan. 2006.

[6] H. A. Krishna, N. K. Misra, and M. S. Suresh

Solar cell as a capacitive temperature sensor

IEEE Trans. Aerosp. Electron. Syst., vol. 47, no. 2, pp. 782-789, Apr. 2011.

[7] H. U. Oh and T. Park

Experimental feasibility study of concentrating photovoltaic power system for CubeSat applications

IEEE Trans. Aerosp. Electron. Syst., vol. 51, no. 3, pp. 1942-1949, Jul. 2015.

[8] S. Pindado, E. Roibas-Millan, A. Garcia, I. Perez-Grande, and J. Perez-Alvarez

The UPMSat-2 satellite : An academic project within aerospace engineering education

in Proc. 2nd Annu. Int. Conf. Eng. Educ. Teaching, 2017, pp. 1-28.

[9] E. Roibás-Millán, A. Alonso-Moragón, A. Jiménez-Mateos, and S. Pindado

Testing solar panels for small-size satellites: The UPMSAT-2 mission

Meas. Sci. Technol., vol. 28, no. 11, pp.1-12, 2017, Art. no. 115801.

[10] E. Rodríguez-Rojo, S. Pindado, J. Cubas, and J. Piqueras-Carreño UPMSat-2 ACDS magnetic sensors test campaign Measurement, vol. 131, pp. 534-545, 2019.

[11] J. P. Grey, I. R. Mann, M. D. Fleischauer, and D. G. Elliott Analytic model for low earth orbit satellite solar power IEEE Trans. Aerosp. Electron. Syst., vol. 56, no. 5, pp. 3349-3359, Oct. 2020.

[12] M. Miyatake, M. Veerachary, F. Toriumi, N. Fujii, and H. Ko Maximum power point tracking of multiple photovoltaic arrays: A PSO approach

IEEE Trans. Aerosp. Electron. Syst., vol. 47, no. 1, pp. 367-380, Jan. 2011.

[13] H. Dehbonei, S. R. Lee, and S. H. Ko

Direct energy transfer for high efficiency photovoltaic energy systems part II: Experimental evaluations

IEEE Trans. Aerosp. Electron. Syst., vol. 45, no. 1, pp. 46-57, Jan. 2009.

[14] H. Dehbonei, S. R. Lee, and H. Nehrir

Direct energy transfer for high efficiency photovoltaic energy systems Part I: Concepts and hypothesis

IEEE Trans. Aerosp. Electron. Syst., vol. 45, no. 1, pp. 31-45, Jan. 2009.

[15] M. Swartwout

The first one hundred CubeSats : A statistical look J. Small Satell., vol. 2, no. 2, pp. 213-233, 2013.

[16] P. Planas-Almazan and D. - C. Flett

ESARAD : From R \& D to industrial utilisation ESA Bull., vol. 93, pp. 61-67, 1998. 
[17] S. Pindado and J. Cubas

Simple mathematical approach to solar cell/panel behavior based on datasheet information

Renew. Energy, vol. 103, pp. 729-738, 2017.

[18] ESA-ESTEC Requirements \& Standards Division, ECSS Standards: Space Engineering - Thermal Analysis Handbook. ESA, Noordwijk, The Netherlands, 2016.

[19] G. Fernández-Rico, I. Pérez-Grande, A. Sanz-Andres, I. Torralbo, and J. Woch

Quasi-autonomous thermal model reduction for steady-state problems in space systems

Appl. Therm. Eng., vol. 105, pp. 456-466, 2016.

[20] I. Torralbo, I. Perez-Grande, A. Sanz-Andres, and J. Piqueras Correlation of spacecraft thermal mathematical models to reference data Acta Astronautica, vol. 144, pp. 305-319, 2018.

[21] A. Gómez-San-Juan, I. Pérez-Grande, and A. Sanz-Andrés Uncertainty calculation for spacecraft thermal models using a generalized SEA method Acta Astronautica, vol. 151, pp. 691-702, 2018.

[22] J. Piqueras, I. Pérez-Grande, A. Sanz-Andres, and I. Torralbo Calculation of linear conductances for thermal lumped models by means of the CMF method Acta Astronautica, vol. 173, pp. 76-85, 2020.

[23] S. Pindado, J. Cubas, E. Roibás, M. Félix, and S. Palmer Project based learning applied to spacecraft power systems: A long term engineering and educational program at UPM University

CEAS Space J., vol. 10, no. 3, pp. 307-323, 2018.

[24] M. Wolf and H. Rauschenbach

Series resistance effects on solar cell measurements Adv. Energy Convers., vol. 3, no. 2, pp. 455-479, 1963.

[25] J. Cubas, S. Pindado, and M. Victoria

On the analytical approach for modeling photovoltaic systems behavior

J. Power Sources, vol. 247, pp. 467-474, Feb. 2014.

[26] M. G. Villalva, J. R. Gazoli, and E. R. Filho

Comprehensive approach to modeling and simulation of photovoltaic arrays IEEE Trans. Power Electron., vol. 24, no. 5, pp. 1198-1208, May 2009.

[27] D. T. Cotfas, P. A. Cotfas, and S. Kaplanis Methods to determine the dc parameters of solar cells: A critical review Renew. Sustain. Energy Rev, vol. 28, pp. 588-596, 2013.

[28] A. K. Tossa, Y. M. Soro, Y. Azoumah, and D. Yamegueu A new approach to estimate the performance and energy productivity of photovoltaic modules in real operating conditions Sol. Energy, vol. 110, pp. 543-560, 2014.

[29] A. Ortiz-Conde, F. J. García Sánchez, and J. Muci New method to extract the model parameters of solar cells from the explicit analytic solutions of their illuminated characteristics Sol. Energy Mater. Sol. Cells, vol. 90, no. 3, pp. 352-361, Feb. 2006.
[30] S. Pindado, J. Cubas, E. Roibás-Millán, F. Bugallo-Siegel, and F. Sorribes-Palmer

Assessment of explicit models for different photovoltaic technologies

Energies, vol. 11, no. 6, 1353.

[31] A. Bellini, S. Bifaretti, V. Iacovone, and C. Cornaro

Simplified model of a photovoltaic module

in Proc. Appl. Electron., 2009, pp. 47-51.

[32] M. U. Siddiqui, A. F. M. Arif, A. M. Bilton, S. Dubowsky, and M. Elshafei

An improved electric circuit model for photovoltaic modules based on sensitivity analysis

Sol. Energy, vol. 90, pp. 29-42, 2013.

[33] H. Ibrahim and N. Anani

Variations of PV module parameters with irradiance and temperature

Energy Procedia, vol. 134, pp. 276-285, 2017.

[34] J. L. Balenzategui

I-V characterization of solar cells with variable intensity monochromatic light

in Proc. 23rd Eur. Photovolt. Sol. Energy Conf. Exhib., 2008, pp. 513-516.

[35] J. L. Balenzategui, I. Rodríguez-Outón, and F. Chenlo

Calibration of crystalline silicon solar cells as reference devices for cell testers and sorters

in Proc. 25th Eur. Photovolt. Sol. Energy Conf. Exhib./5th World Conf. Photovolt. Energy Convers., 2010, pp. 2642-2648.

[36] J. L. Balenzategui, J. Cuenca, I. Rodríguez-Outón, and F. Chenlo Intercomparison and validation of solar cell I-V characteristic measurement procedures

in Proc. 27th Eur. Photovolt. Sol. Energy Conf. Exhib., Frankfurt, Germany, 2012, pp. 1471-1476.

[37] M. Uno and K. Tanaka

Spacecraft electrical power system using lithium-ion capacitors IEEE Trans. Aerosp. Electron. Syst., vol. 49, no. 1, pp. 175-188, Jan. 2013.

[38] J. Meseguer, I. Pérez-Grande, and A. Sanz-Andrés

Spacecraft Thermal Control. New York, NY, USA: Elsevier, 2012.

[39] D. G. Gilmore

Spacecraft Thermal Control Handbook, vol. I, 2nd ed., El Segundo, CA, USA: The Aerospace Press, 2002.

[40] W. Guter et al.

Current-matched triple-junction solar cell reaching $41.1 \%$ conversion efficiency under concentrated sunlight efficiency under concentrated sunlight

Appl. Phys. Lett., vol. 94, no. 22, 2009, Art. no. 223504

[41] J. Cubas, A. Farrahi, and S. Pindado

Magnetic attitude control for satellites in polar or sunsynchronous orbits

J. Guid. Control. Dyn., vol. 38, no. 10, pp. 1947-1958, 2015.

[42] Arianespace. VEGA: User's Manual. Evry-Courcouronnes, France: Arianespace, 2014.

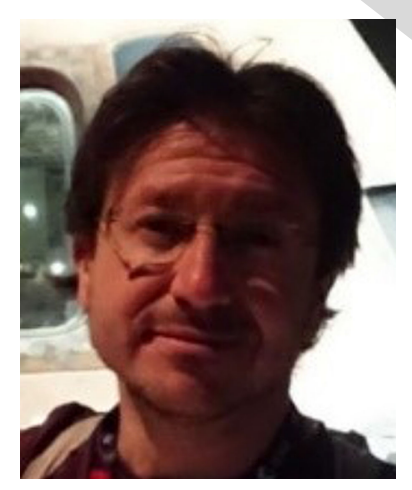

Alejandro M. Gomez-San-Juan received the B.Sc. degree in aeronautical engineering, the M.Sc. and Ph.D. degrees in aerospace engineering from the Technical University of Madrid (UPM - Universidad Politécnica de Madrid), Madrid, Spain, in 2010, 2013, and 2018, respectively.

He is a Full-Time Researcher with Instituto Universitario de Microgravedad Ignacio da Riva (IDR / UPM), Madrid, Spain. His research interest includes space systems, mainly in thermal control and mechanical engineering. He has participated in a number of international scientific missions, such as ESA's Solar Orbiter and ExoMars-2018, CNSA's Chang'E 4 or UPMSat-2, the latter in the framework of H2020 program of the EU. 


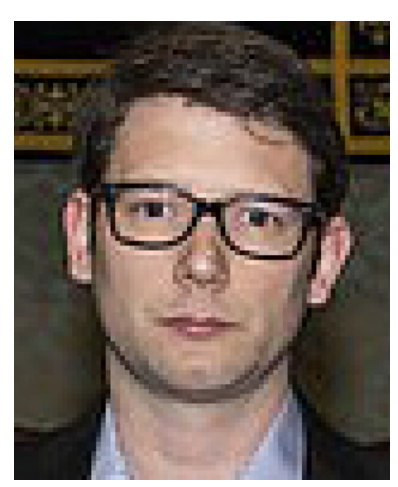

Javier Cubas received the B.Sc. degree in aeronautical engineering, the M.Sc. and Ph.D. degrees in aerospace engineering from the Technical University of Madrid (UPM Universidad Politécnica de Madrid), Madrid, Spain, in 2010, 2012, and 2015, respectively.

$\mathrm{He}$ is an Assistant Professor with the Aerospace Systems, Air Transport and Airports Department, Technical University of Madrid, Madrid, Spain. He teaches in the Aerospace Engineering Degree, the Master's Degree in Aerospace Engineering, and the Master's Degree in Space Systems. He has done research stays with Yale University, New Haven, CT, USA, in 2015 and Ryerson University, Toronto, ON, Canada, in 2017.

Dr. Cubas is a member of the Instituto Universitario de Microgravedad Ignacio da Riva (IDR / UPM) and of the Development and Aerospace Testing Research Group, where he develops his research in photovoltaic energy, space systems (mission analysis, power subsystem, and attitude control) and air transport.

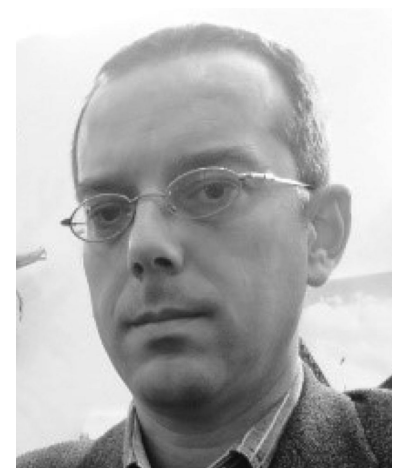

Santiago Pindado received the M.Sc. and Ph.D. degrees in aerospace engineering from the Technical University of Madrid (UPM - Universidad Politécnica de Madrid), Madrid, Spain, in 1995 and 2003, respectively.

He is Professor with UPM since 2003. He worked for SENER from 1996 to 1999, being involved in aerodynamics and fluid mechanics computer simulations. In 1999, he started his doctoral studies in experimental and civil aerodynamics, with the IDR/UPM Research Institute, Madrid, Spain, under the supervision of Prof. José Meseguer. He was also involved in the development of the Spanish User Support Operation Centre (USOC), responsible for running and implementing European payloads (mostly related to the Fluid Science Lab) on the International Space Station. In 2008, he became responsible for the development of the UPMSat-2 power subsystem, as one of his tasks within IDR/UPM research programs. Additionally, he has held different executive positions with UPM as IDR/UPM Deputy Director, Head of Studies of the UPM Master Program in Space Systems (MUSE), or Technical Director of the LAC-IDR/UPM calibration lab. He teaches several subjects related to power systems (from airports power networks to satellites power subsystems) with the Aerospace Eng. Faculty, UPM, and has authored or coauthored numerous publications regarding a wide scope of academic/research subjects such as spacecraft power and control subsystems, power networks, lighting quality, experimental aerodynamics, and performance of wind speed measurement instruments. 